\title{
Production and Evaluation of Biodegradable Plastic Films and their Resistance to Organic solvents
}

\author{
*1 BASSEY, P; ${ }^{1}$ SALOKUN, O ${ }^{2}$ AGHEDO, ON; ${ }^{3}$ HASSAN, IS \\ Department of Science Laboratory Technology, Faculty of Life Sciences, University of Benin, Benin-City, Edo State, Nigeria \\ *Corresponding Author Email: peter.bassey@uniben.edu; Tel: +2348066834634
}

\begin{abstract}
The character of gelatinized cassava starch was studied with a view to deciphering its rate of organic solvent absorption. Solution casting method was employed in fabricating the cast films. Cassava starch (CS) was initially modified to produce thermoplastic starch (TPS) and Polyvinyl alcohol (PVA) added to the matix. Absorption test was also carried out by introducing glycerol into the mixture to completely gelatinize the blend. Each blended sample was dried in a closed vessel for 12 hours and then cured in the oven for half an hour at $80^{\circ} \mathrm{C}$. Finally, the film was peeled off from the glass plate and sealed for experimental use. Results revealed that increase in polyvinyl alcohol content produced a corresponding increase in organic solvent uptake rate. However, this results implies that the cast films could absorb more water (hydrophilic) and microorganisms in a soil water environment increasingly over time with an increasing starch content, thus leading to a greater biodegradation.
\end{abstract}

DOI: https://dx.doi.org/10.4314/jasem.v23i11.18

Copyright: Copyright $(\subset 2019$ Bassey et al. This is an open access article distributed under the Creative Commons Attribution License (CCL), which permits unrestricted use, distribution, and reproduction in any medium, provided the original work is properly cited.

Dates: Received: 07 October 2019; Revised: 11 November 2019; 24 November 2019

Keywords: Biodegradable, resistance, gelatinization, thermoplastic.

Starch is a polymeric hydrocarbon made up of anhydroglucose units, and used to form biodegradable starch coatings. Such production is characterized by low cost and good mechanical properties (Xu et al., 2005). Jolanta et al. (2018) described corn starch has been a good source for creating films, and that it consists of $25 \%$ amylase and $75 \%$ amylopectin. They also reported that starch is a very promising material that occurs in many plants, completely degradable in soil and water, and supports the process of biodegradation of biodegradable mixed plastics. Starch has been treated in an extruder by the use of mechanical thermal energy to be converted into the thermoplastic material (Mitrus et al., 2016). In the manufacturing of thermoplastic starch plasticizers, it reduces the hydrogen bonds within the molecular level to ensure the stability of properties of the product (Jolanta et al., 2018). Earlier works carried out on the synthesis of biodegradable plastics in solving the plastic waste disposal problem that have been reported in different parts of the world (Idris, 2012; Shen \& Burgess, 2012; Potarniche, 2012; Dufresne and Thomas, 2013; Thakur et al., 2014; Cinelli, 2014; Frone, 2014). Adriana et al. (2015) reported that despite the low price and high availability of starch, important drawbacks related to poor mechanical and thermal properties, brittleness and high moisture sensitivity have to be overcome to increase starch attractiveness for large-scale application. With this aim, starch was modified or blended with other materials (Kumar \& Singh, 2008; Müller et al., 2009; Rahman et al., 2010; Campos et al., 2012; Noushirvani et al., 2012; Priya et al., 2014; Panaitescu et al., 2015), moreover, due to its biodegradability, high polar character, good mechanical properties and easy processing, polyvinyl alcohol (PVA) is suitable for starch modification and many studies on starch/PVA have been reported (Sin et al., 2010; Chaléat et al., 2012). They further reported that strong hydrogen bonding between starch and PVA and the formation of a network structure were observed in starch - PVA blends with more than $30 \%$ PVA. According to them, although biodegradation is mandatory for environmental purposes, the lifetime as well as thermal and water stability of starch based materials has to be improved for covering more application fields. It is believed that when starch is blended with polyvinyl alcohol, it acts as a weak link between the polyvinyl alcohol matrix and this becomes a point of attack by microorganisms which leads to disintegration of the plastic composite. This work is therefore aimed at producing biodegradable plastic films and evaluating their resistance to organic solvents.

\section{MATERIALS AND METHOD}

Materials: Materials used for this study include Polyvinyl alcohol (PVA), which was obtained from Roosevelt Chemical Limited, Benin-City. Other materials used include Acetone, Methyl chloride, 
Toluene, Glycerol, Distilled water and Granulated Cassava starch.

Methods: Films were fabricated by solution casting method. Polyvinyl alcohol (PVA) and cassava starch (CS) were weighed into 2-sets of five different petridishes in the following grams ; $10 \mathrm{~g}, 8 \mathrm{~g}, 6 \mathrm{~g}, 4 \mathrm{~g}, 0,2 \mathrm{~g}$, $4 \mathrm{~g}, 6 \mathrm{~g}, 10 \mathrm{~g}$, respectively. The calculated amount of PVA and CS were mixed and the mixture was slowly added to $40 \mathrm{ml}$ distilled water at room temperature with stirring.

When completely suspended, the temperature of the mixture was slowly raised to $80^{\circ} \mathrm{C}$, maintaining the stirring but avoiding frothing. Glycerol was then added to the mixture and the stirring maintained for an hour and thirty minutes to completely gelatinize the starch. The volume of the slurry was maintained by adding a little distilled water during this period. After that, the mixture was removed from the heat and casted onto a glass plate which was placed on a flat surface. The blended sample was dried in a closed place for almost 12 hours and then cured in the oven for half an hour at $80^{\circ} \mathrm{C}$. Finally, the film was peeled off from the glass plate and sealed for experimental use. The step above was repeated for the rest of the samples. Polyvinyl chloride (PVA)/Thermoplastic starch (TPS) composition are shown in Table 1 below

\begin{tabular}{llll}
\multicolumn{4}{c}{ Table 1: Formulation for PVA/CS Blend } \\
\hline $\begin{array}{l}\text { Blend ratio } \\
\text { (g) }\end{array}$ & $\begin{array}{l}\text { PVA } \\
(\%)\end{array}$ & $\begin{array}{l}\text { TPS } \\
(\%)\end{array}$ & $\begin{array}{l}\text { Glycerol } \\
(\%)\end{array}$ \\
\hline $10: 0$ & 100 & 0 & 20 \\
$8: 2$ & 80 & 20 & 20 \\
$6: 4$ & 60 & 40 & 20 \\
$4: 6$ & 40 & 80 & 30 \\
$0: 10$ & 0 & 100 & 40 \\
\hline
\end{tabular}

Solvent absorption test: Three pieces per test samples of the different composites were cut and dried in oven for 2 hours at $85^{\circ} \mathrm{C}$, followed by cooling, and was immediately weighed. The samples were entirely immersed in air-tight bottles containing the respective solvents: Toluene, Methyl Chloride and Acetone. The samples were removed from the bottles containing the various solvents after twenty minutes, wiped dry with a soft, clean dry cloth, to remove excess solvent from the surface of the samples and re-weighed immediately. This procedure was carried out for: 40 , 60 and 80 minutes time intervals. The change in weight was calculated as solvent uptake.

$\%$ Swelling $=\frac{(W 2-W 1)}{W 1} \times$

Where $\mathrm{W}_{1}$ and $\mathrm{W}_{2}$ are the initial weight and final weight of the samples, respectively.

\section{RESULT AND DISCUSSION}

Results of \% Sorption in Toluene, Methyl Chloride and Acetone of Thermoplastic starch (TPS)/Polyvinyl Alcohol (PVA) Blends (Cast Films) at different time intervals.

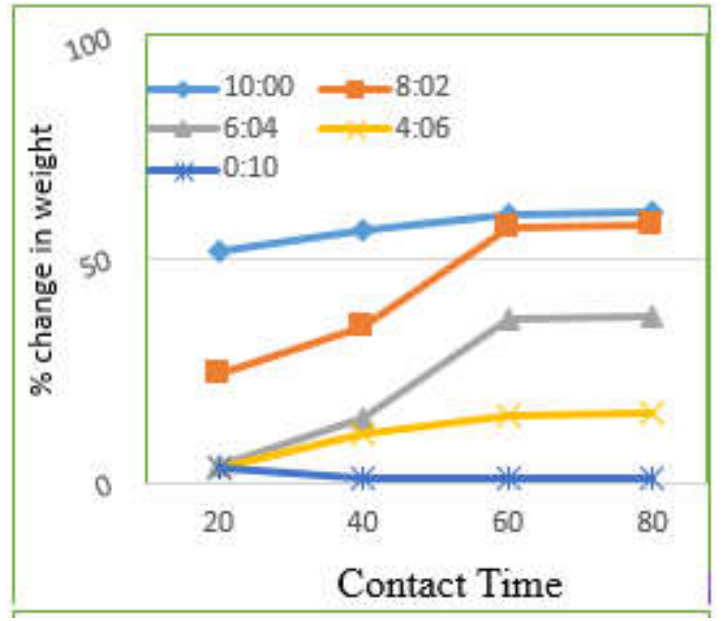

Fig 1: Graph of PVA/TPS Cast Film Absorption Rate in Toluene

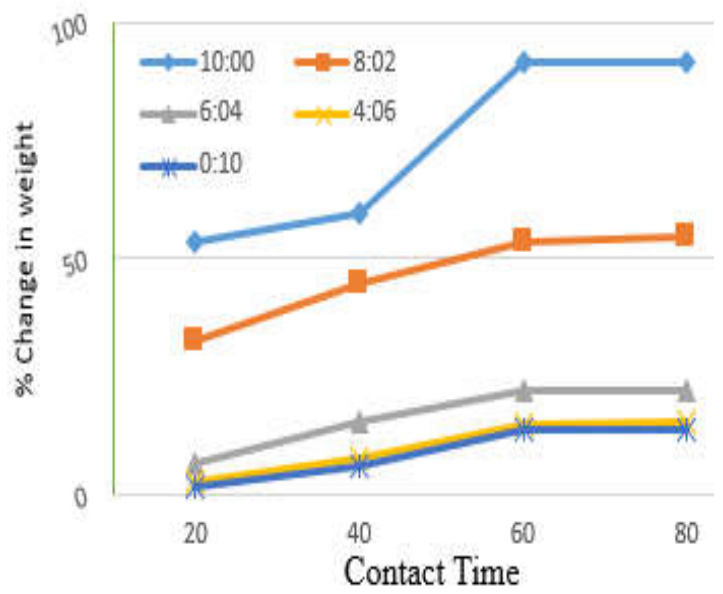

Fig 2: Graph of PVA/TPS Cast Film Absorption Rate in Methyl Chloride

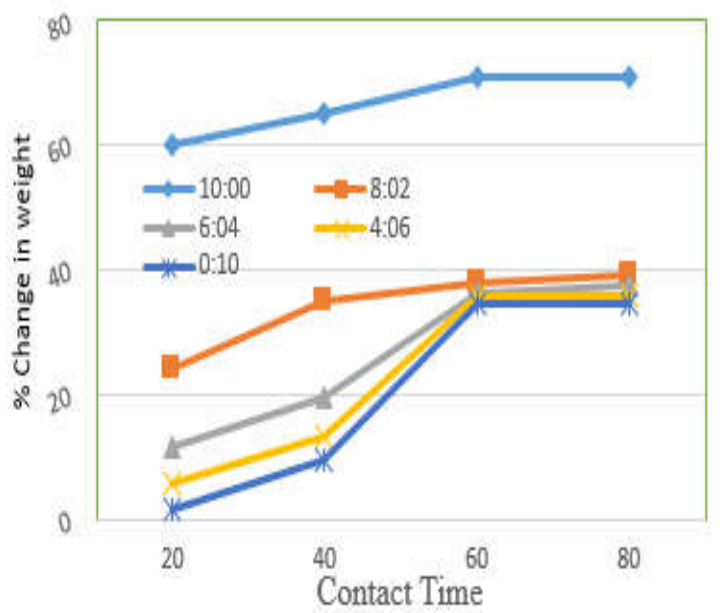

Fig 3: Graph of PVA/TPS Cast Film Absorption Rate in Acetone 
The results obtained from this study revealed generally, that solvent uptake increases with time, except for that of PVA/TPS Cast Film Absorption Rate in Toluene (in proportion of $0: 10$ ) where the film was completely thermoplastic starch, and showed an initial down trend direction (indicating a decrease in solvent uptake) and then became constant. Moreover, there was a general decrease in the rate of organic solvent uptake as the polyvinyl alcohol content decreases, as against increase in water (hydrophilic) uptake by the blend reported by Azahari et al. (2011). Their findings revealed said that PVA films that contained starch demonstrated higher water uptake than the pure PVA films. Water uptake increased with increasing immersion time and starch content. This finding is due to the hydrophilic character of natural starch, which is responsible for the water absorption in the composites, therefore, a higher starch content led to a higher amount of water being absorbed (Kale et $a l .$, 2007). The gelatinised starch favoured degradation of the blends when immersed in water; this was likely due to the rupture of the grains during starch gelatinization (Rosa et al., 2004).

Conclusion: Conclusively, it could be generalized that natural starch decreases the tensile strength of the blend as it can permit the increased action of microorganisms to bring about biodegradation, and which could help in curbing the environmental consequences of employing the petroleum-based plastics counterpart.

Acknowledgement: The author wish to acknowledge Dr. P. O. Okonji, the Chief Technologist of Chemistry Department, University of Benin, for granting us access to the laboratory facilities in carrying out this research.

\section{REFERENCES}

Adriana, N. F., Cristian, A. N., Raluca, A. G., Denis, M. P. (2015). Thermal properties of water resistant starch - polyvinyl alcohol films modified with cellulose nanofibers. Polymer Degradation and Stability 121(11): 386-387.

Azahari, N. A. Othman, N. and Ismail, H. (2011). Biodegradation Studies of Polyvinyl Alcohol/Corn Starch Blend Films in Solid and Solution Media. Journal of Physical Science, Vol. 22(2), 15-31.

Bin, G., Dongdong, Z., Bengang, L., Peng, Y., and Panxin, Li. (2018). Polyvinyl Alcohol Microspheres Reinforced Thermoplastic Starch
Composites. MDPI, Basel, Switzerland. Pp1, 11, 640.

Campos, A., Marconcini, J. M., Martins-Franchetti, S. M., Mattoso, L. H. C. (2012). The influence of UV-C irradiation on the properties of thermoplastic starch and polycaprolactone biocomposite with sisal bleached fibers. Polym Degrad Stab; 97:1948-1955.

Chaléat, C. M., Halley, P. J., Truss, R. W. (2012). Study on the phase separation of plasticised starch/poly(vinyl alcohol) blends, Polym Degrad Stabil; 97:1930-1939.

Cinelli, P., Schmid, M., Bugnicourt, E., Wildner, J., Bazzichi, A., Anguillesi, I., Lazzeri, A. (2014). Whey protein layer applied on biodegradable packaging film to improve barrier properties while maintaining biodegradability. Polym Degrad Stab.; 108:151-157.

Dufresne, A., Thomas, S., Pothan, L. A. (2013). Biopolymer Nanocomposites: Processing, Properties, and Applications. Wiley Series on Polymer Engineering and Technology. Grossman RF, Nwabunma D. Eds.; Wiley.

Frone, A. N., Berlioz, S., Chailan, J. F., Panaitescu, D. M. (2013). Morphology and thermal properties of PLA-cellulose nanofibers composites. Carbohydr Polym; 91:377-384.

Idris, A., Misran, E., Hassan, N., Abd, J.A. and Seng, C.E. (2012). Modified PVA-alginate encapsulated photocatalystferrophoto gels for Cr(VI) reduction. J. Hazard. Mater., 227-228, 309-316.

Jolanta, W-K., Tomasz, R., Gabriel, B., Mieczysław, S., Tomasz, K., and Vijay, K. T. (2018). Recent Progress In Biodegradable Polymers And Nanocomposite- Based Packaging Materials For Sustainable Environment. International Journal of Polymer Analysis and Characterization. DOI: 10.1080/1023666X.2018.1455382. pp 2-5.

Kale, G., Kijchavengkul, T., Auras, R., Rubino, M., Selk, S. E. \& Singh, S. P. (2007). Compostability of bioplastic packaging materials: An overview. Macromol. Biosci., 7(3), 255-277. 21.

Kumar, A. P., Singh, R. P. (2008). Biocomposites of cellulose reinforced starch: Improvement of properties by photo-induced crosslinking. Bioresour Technol; 99:8803-8809. 
Mitrus, M., Combrzyński, M., Kupryaniuk, K., Wójtowicz, A., Oniszczuk, T., Kręcisz, M., Matysiak, A., Smurzyńska, A., and Mościcki, L. (2016). A study of the solubility of biodegradable foams of thermoplastic starch. J. Ecol. Eng. 17:184-189.

Müller, C. M. O., Laurindo, J. B., Yamashita, F. (2009). Effect of cellulose fibers on the crystallinity and mechanical properties of starchbased films at different relative humidity values. Carbohydr Polym; 77:293-299.

Noushirvani, N., Ghanbarzadeh, B., Entezami, A. A. (2012). Effect of cellulose nanocrystal and polyvinyl alcohol on the physical properties of starch based bionanocomposite films. Iran J Nutr Sci Food Technol; 7(1).

Panaitescu, D. M., Frone, A. N., Ghiurea, M., Chiulan, I. (2015). Influence of storage conditions on starch/PVA films containing cellulose nanofibers. Ind Crops Prod; 70:170-177.

Potarniche, C. G., Vuluga, Z., Donescu, D., Christiansen, J. de C., Eugeniu, V., Radovici, C., Serban, S., Ghiurea, M., Somoghi, R., Beckmannd, S. (2012). Morphology study of layered silicate/chitosan nanohybrids. Surf Interface Anal; 44:200-207.

Priya, B., Gupta, V. K., Pathania, D., Singha, A. S. (2014). Synthesis, characterization and antibacterial activity of biodegradable starch/PVA composite films reinforced with cellulosic fibre. Carbohydr Polym; 109:171-179.
Rahman, W. A., Sin, L. T., Rahmat, A. R., Samad, A. A. (2010). Thermal behaviour and interactions of cassava starch filled with glycerol plasticized polyvinyl alcohol blends. Carbohydr Polym; 81:805-810.

Rosa, D. S., Guedes, C. G. F., Pedroso, A. G. \& Calil, M. R. (2004). The influence of starch gelatinization on the rheological, thermal, and morphological properties of poly(-caprolactone) with corn starch blend. Mater. Sci. Eng. C, 24(5), 663-670. 22.

Shen, J.; Burgess, D.J. Accelerated in vitro release testing of implantable PLGA microsphere/PVA hydrogelcomposite coatings. Int. J. Pharm. 2012, 422, 341-348.

Sin, L. T., Rahman, W. A., Rahmat, A. R., Khan, M. I. (2010). Detection of synergistic interactions of polyvinyl alcohol-cassava starch blends through DSC. Carbohydr Polym; 79:224-226.

Thakur, V. K., Thakur, M. K., Raghavan, P., Kessler, M. R. (2014). Progress in green polymer composites from lignin for multifunctional applications: a review. ACS Sustainable Chem Eng; 2:1072-1092.

Xu, Y. X., Kim, K. M., Hanna, M. A. and Nag, D. (2005). Chitosan-starch composite film: Preparation and characterization. Ind. Crops Prod. 21:185-192. 